\title{
Facial self-perception: Its relation to objective appearance and self-concept
}

\author{
JOHN B. PITTENGER and LINDA MUSUN BASKETT \\ University of Arkansas, Little Rock, Arkansas
}

\begin{abstract}
The ability to judge objectively the physical attractiveness of one's own face and the relation of these judgments to self-concept were assessed. Thirty white female and 34 white male college students rated the physical attractiveness of their own faces, once without viewing their faces (memory condition) and once while viewing photographs of their faces and the faces of the other same-sex subjects (photograph condition). Self-concept was assessed by administration of the Tennessee Self Concept Scale. There was a significant positive correlation between subjects' ratings of their own attractiveness and those they received from others. However, using the mean rating by others as an objective measure of appearance, subjects were also found to overestimate significantly the attractiveness of their own faces in both the memory and photograph conditions. Only a limited relationship between self-concept and self-perception was found. Overestimation of attractiveness was significantly correlated with more positive physical selfconcepts only in the memory condition. None of the self-concept scores were significantly correlated with the attractiveness ratings by others.
\end{abstract}

A person's facial attractiveness is known to be an important factor in how others react to that person in a wide variety of situations. It is generally agreed that observers have both a strong consensus about what constitutes a physically attractive face and a clear stereotype of the characteristics and behaviors expected of attractive individuals (Adams, 1977b; Berscheid, 1980; Berscheid \& Walster, 1974). These reactions by others may shape our own social behavior and the concept of self that we develop (Adams, 1977a, 1977b). If we apply these standards and stereotypes to ourselves, then how attractive we perceive ourselves to be should be related to how positively we think of ourselves.

Although a body of research exists showing a relation between body image and self-concept (e.g., Lerner, Orlos, \& Knapp, 1976; Rosen \& Ross, 1968; Zion, 1965), relatively little work on facial self-perception and self-concept is available. The most relevant study is Korabik and Pitt's (1980) analysis of the accuracy of self-perception and its relation to self-concept. Using mothers of orthodontic patients as their subjects, they studied accuracy of self-perception and its relation to self-concept. Self-perception was assessed by requiring subjects to pick silhouette drawings most like their own faces from a series of five drawings of female faces graded in degree of protrusiveness of the lower

This research was supported by the Marie Wilson Howells bequest to the Psychology Department, University of Arkansas at Little Rock, and by NIDR Grant DE0490-02. We thank Michael Brown, Mary Herren, Martha Levansaler, and Ann Orlicek for assistance in collection of the data. Requests for reprints should be sent to the first author at the Department of Psychology, University of Arkansas, 33rd \& University, Little Rock, AR 72204. face. Each subject's objective appearance was assessed by having orthodontists select, from the female series, the drawing that best matched a photograph of that subject's face. An accurate self-perception was defined as one in which the profile selected by the person matched the one selected by the orthodontists. Subjects also selected the ideal face from the female series and from a similar series of five male faces. Bill's Index of Adjustment served as the measure of self-concept. In this scale, favorableness of self-concept is determined by the difference between the real-self and ideal-self scales.

Several of Korabik and Pitt's (1980) conclusions are directly relevant to the present study. First, they interpreted their results as showing generally accurate selfperception: $57 \%$ of their subjects picked the same drawing that the orthodontists picked as most closely matching their own faces, and, treating the five-face continuum as a numerical scale, the product-moment correlation of the self and orthodontists' choices was .39. In other relevant work, Adams (1977a) found a median correlation of .37 in a study comparing assessments by subjects and independent observers of the subjects' facial attractiveness, body type, and general appearance. In the Lewit and Virolainen (1968) study, the correlation between actual and self-perceived orthodontic condition was found to be .46 .

Although Korabik and Pitt (1980) found no significant overall relation $(\mathrm{r}=-.05)$ between objective appearance and self-concept, self-concept did appear to be related to self-perception. They found lower selfesteem to be associated with greater discrepancy between the profile selected by the subject as being like herself and her ideal profile. This is similar to Cremer and Hukill's (1969) and Zion's (1965) findings for 
self-concept and body image. They also found that the direction of error in self-perception was related to self-concept. Among those subjects making errors, that is, not picking the same drawing that the orthodontists picked, those with high self-concepts tended to see themselves as closer to the ideal than they actually were. On the other hand, those with low self-concepts tended to rate their own faces as further from the ideal than others saw them to be.

Overall, Korabik and Pitt (1980) concluded that facial self-perception is moderately accurate and may serve as a moderating variable linking self-concept and objective appearance. In their study, self-perception was measured by a subject's selection of which profile looked most like herself. The standard for measuring discrepancy between self-perception and perception by others was the match between the profile a woman selected as most like her own and the one selected by orthodontists as most like her. Subjects were not asked to rate how attractive they thought either profile to be. It is this type of evaluative statement about one's appearance that may be most relevant to one's overall self-esteem. It is possible that people may not be accurate in matching their profiles and may perceive themselves as being different from their ideal profiles and still view themselves as highly attractive. In addition, mothers of orthodontic patients might not be a representative sample of the general population. As a result of their children's problems, these women might be especially sensitive to some aspects of facial appearance and make judgments different from those made by people not concerned with orthodontic treatment. Finally, potential sex differences in these judgments would not have been found with Korabik and Pitt's methods.

The present study addressed the same questions about facial self-perception and its relationship to self-concept, but with considerable changes in the methods. In this study, the subjects made two ratings of their own facial attractiveness: once from memory, to assess the self-perception they used in everyday life, and once while viewing their own photographs, to ascertain whether or not information on their actual appearance would change their assessments. The extent to which a person's judgment of his or her own facial attractiveness agreed with the judgment made by others was also assessed. Although orthodontists are experts in judging facial attractiveness, their judgments may not be the same as the subjects' peers. Peer judgments seem to us the ones most relevant to possible effects on the development of self-concept. Thus, each participant's facial self-perceptions were compared with the ratings of his or her face made by other participants in the study. The Tennessee Self Concept Scale was used in place of Bill's Index to assess self-concept. This self-concept scale is based on the number of positive self-descriptive statements and provides subscales for different aspects of self-concept.

\section{METHOD}

\section{Participants}

Thirty-four white male and 30 white female students in introductory psychology classes participated in the study on a voluntary basis and were paid $\$ 10$ to participate. Subjects with glasses, beards, or mustaches obscuring parts of their faces were not accepted for participation. The male and female groups were tested separately so that attractiveness judgments were made by participants of the same sex as the subject. This was done in order to get an attractiveness rating that would be more appropriate for comparison with one's own. Opposite-sex judgments of a person's attractiveness might not be an appropriate objective standard for one's judgment of one's own attractiveness.

\section{Procedure}

During initial recruitment, potential volunteers were told the nature of the study and the payment they would receive. They were informed that the purpose of the study was to examine the relationship between people's perception of their own faces and the perception of their faces by others.

The study was conducted in three phases. During Phase I, a Polaroid camera with a flash attachment was used to take two color photographs, one of the front view and one of the right profile, of the participant. In order to control for possible differences in attractiveness ratings due to differences in facial expressions, the participants were asked to maintain neutral facial expressions, neither smiling nor frowning. The subjects were then asked to rate the attractiveness of their own faces on a 7-point scale, without referring to the photograph. The scale ranged from "not very attractive" (1) through "neither especially attractive nor unattractive" (4) to "very attractive" (7). Each person was assigned an identification number, and that number was used to record and collate all data collected from that participant.

Between Phase I and Phase II, the photographs were mounted in a loose-leaf binder. Each pair of photographs was mounted on one page of black mounting paper. Black paper was also used to mask out the hair and clothing of the person.

Since personal knowledge of other participants might bias ratings of facial attractiveness, ratings of of participants' familiarity with each other were collected in Phase II. The participants viewed the photos of all the others in their group and rated their familiarity with each on a 5-point scale. A rating of 1 meant "I don't know this person at all," and a rating of 5 meant "I know him/ her fairly well and could describe what type of person he/she is."

The purpose of Phase III was to obtain the attractiveness ratings of the photos by each subject, including a rating of his or her own photo, and self-concept measures on each participant. The photos were shuffled after each subject's rating to randomize for possible order effects. However, to control for possible comparison effects based on how many other photos had appeared before his or her own, each subject saw his or her photo in the 11 th position. Ratings were made on the same 7-point scale used in Phase I. The subjects were informed that their own photographs would be included in the album and were instructed to attempt to be as objective as possible when rating their faces, that is, to treat their own faces just as they did those of others. Finally, the Tennessee Self Concept Scale was administered.

\section{RESULTS}

\section{Distribution of Physical Attractiveness}

Excluding self-ratings and ratings by friends (scores of 4 or 5 on the familiarity scale), mean attractiveness scores of individual faces ranged from 1.84 to 5.26 on the 7-point scale (i.e., between "moderately less attractive 
than average" and "slightly more attractive than average"), with a mean of 3.64 over all 64 faces. The sample thus included a reasonably wide range of levels of attractiveness.

\section{Accuracy of Self-Perception}

We shall use the term "error" to refer to differences between self-ratings and ratings by other subjects. Although the judgments by others of a person's facial attractiveness do not constitute a completely objective measure of appearance, they do represent the best available estimate. Additionally, these judgments are the most relevant for studies of self-concept development, since they form the basis for the feedback a person receives about his or her appearance. Participants' ability to judge accurately and objectively their own facial attractiveness was assessed in two ways: by the magnitude of the difference between each person's ratings and those made by other participants and by the magnitude of the correlation between ratings by each person and those by others.

Accuracy of self-perception was assessed for both the memory condition (in which subjects did not have access to their own photographs) and the photograph condition. For each person, memory error was defined as the value of that person's own memory rating minus the mean rating of his or her face by others. The photograph error was the photograph rating minus the mean of ratings by others. Positive error scores therefore represented overestimates in the self-perception of attractiveness, whereas negative error scores represented underestimates.

Testing the two types of errors together in a multivariate analysis of variance, we found that both memory errors $[F(2,62)=132.33, p<.001]$ and photograph errors $[F(2,62)=11.50, p<.01]$ were significantly greater than zero. No effect of sex was found for either error. Mean errors were +1.34 in the memory condition and +0.52 in the photograph condition.

These results show that observers tend to overestimate the attractiveness of their own faces. This tendency is stronger in the memory condition; again using a multivariate analysis of variance, we found that memory ratings were significantly greater than photograph ratings $[F(1,62)=26.21, p<.001]$. The mean difference was +.82 . As before, there was no effect of sex. Thus, observers seem able to be more objective in the photograph condition.

Accuracy can also be assessed by computing productmoment correlation coefficients between the self-ratings and those made by others. The correlations for both self-ratings were significant [for memory ratings, $\mathrm{r}(64)=$ $.47, \mathrm{p}<.001$; for photograph ratings, $\mathrm{r}(64)=.40$, $\mathrm{p}<.001]$.

\section{Distribution of Self-Concept Scores}

To check the representativeness of our sample of participants, we compared the mean scores of the seven Tennessee subscales and of the total scores of our sample with the means of Fitts's (1964) sample of 626 people. Since the means for our participants fell between -.58 and +.21 standard deviations of Fitts's means, our sample appears to have yielded normal self-concept scores.

\section{Relation of Self-Concept to Self-Perception}

The relation of self-concept to self-perceived facial attractiveness was assessed by computing productmoment correlation coefficients between the ratings in the memory and photograph conditions and the seven Tennessee subscales. In the memory condition, the greatest correlation was with the physical self-concept scale $[r(64)=.36, p<.01]$. The next greatest was with the total score scale $[r(64)=.20, p<.05]$. For the photograph condition, the greatest correlation was again with the physical scale. This correlation was not, however, significant $[\mathrm{r}(64)=.19, \mathrm{p}>.05]$. No other correlations, for either condition, were significant.

\section{Relation of Self-Concept to Error in Self-Perception}

Correlations were computed between errors in the memory and the photograph self-perception conditions with scores on the Tennessee physical self-concept scale. A significant correlation was found for memory errors $[r(64)=.22, p<.05]$ but not for photograph errors $[r(64)=.07, p>.05]$. Thus, in the memory condition, greater errors in self-perception-typically, errors of overestimation of attractiveness - were accompanied by more positive physical self-concepts. For neither type of self-perception error were the correlations with Tennessee total self-concept score significant at the .05 level.

\section{Self-Concept and Objective Appearance}

The correlation coefficients between mean attractiveness ratings by others and the Tennessee subscales and the total score ranged between -.02 and +.17 . None of these was significant at the .05 level.

\section{DISCUSSION}

The results of this study provide at least partial answers to four questions about the relationships among facial self-perception, perception by others, and self-concept. The first question is whether or not other people's perceptions of a person's facial attractiveness and their subsequent behavior toward that person influence the development of his or her self-concept. If there were such an influence, it would be reasonable to expect a correlation between people's self-concept scores and others' ratings of their facial attractiveness. This study, however, found no significant correlations between others' ratings of facial attractiveness and any of the self-concept scores. On the other hand, significant correlations were found between the ratings made by others and both measures of self-perception, as well as between memory self-perception and physical self-concept. This at least suggests that, if a correlation existed between self-concepts and others' perceptions, it would have been found. Also, in spite of the differences in subjects and in methods of assessing appearance and self-concepts, both the present study and that of Korabik and Pitt (1980) failed to find a relationship.

Second, on the question of whether or not people apply society's general aesthetic standards to their own facial appearance, the data suggest a strongly qualified affirmative. The sig- 
nificant correlations of both memory and photo self-perceptions with the ratings by others suggest that similar criteria are used in the two judgments. Adams (1977a), Korabik and Pitt (1980), and Lewit and Virolainen (1968) have found similar correlations between self-perception and others' perceptions. However, it is also clear that evaluations by oneself and by others are not identical. This is shown by the relatively low proportion of variance accounted for by the correlations and by the consistent pattern of overestimation in the subjects' self-ratings.

Third, it was found that people's ratings of their own facial attractiveness do have a significant relationship to their selfconcepts. However, this seems to be limited to how positively a person feels about his or her body and physical appearance in general. Unlike Korabik and Pitt (1980), we did not find any significant relationships between measures of facial self-perception and general self-esteem.

Fourth, it has been suggested that self-concept could serve as a mediating variable in the relation between self-perception and objective appearance. Korabik and Pitt (1980) supported this idea with several analyses showing relations between errors in self-perception and level of self-esteem. Cremer and Hukill (1969) and Zion (1965) have found a similar relationship in their studies of body image and self-concept. Although parallel results were found in the present study, our results suggest the moderating influence is rather narrowly limited. A relation between self-concept and self-perception error was found only for errors in memory ratings and only with the physical self-concept. No relation was found for errors in the photo condition or for total self-concept.

Finally, two general comments on this and related studies should be made. First, although both Korabik and Pitt's (1980) study and our study asked much the same questions, there were great differences in subject characteristics and in the methods of assessing self-perception and self-concept. Whereas some effects were robust enough to be significant in both studies, others were not. Additionally, all the effects, even those that appear in both studies, were relatively weak in terms of the percentage of variance accounted for. It appears that firm conclusions about the accuracy of self-perception and about its exact relation to self-concept can be drawn safely only from patterns that emerge from a group of studies using a variety of measures of self-perception and self-concept. Furthermore, even if future studies reveal consistent patterns in the correlations among self- perception, perception by others, and self-concept, the low values of the correlations suggest that a full understanding of their relations are likely to require attention to factors not yet considered in research to date.

\section{REFERENCES}

Adams, G. R. (1977a). Physical attractiveness, personality, and social relations to peer pressure. Journal of Psychology, 96, 287-296.

Adams, G. R. (1977b). Physical attractiveness research: Toward a developmental social psychology of beauty. Human Development, 20, 217-239.

Berscheid, E. (1980). An overview of the psychological effects of physical attractiveness. In G. W. Lucker, K. A. Ribbens, \& J. A. McNamara, Jr. (Eds.), Psychological aspects of facial form. Ann Arbor, MI: Center for Human Growth and Development.

Berscheid, E., \& Walster, E. (1974). Physical attractiveness. In L. Berkowitz (Ed.), Advances in experimental social psychology (Vol. 7). New York: Academic Press.

Cremer, A. G., \& Hukill, M. A. (1969). Relationship between weight-height ratios, other body measurements, and self-perception of body contours. Research Quarterly, 40, 30-38.

Firts, W. H. (1964). Tennessee Self Concept Scale. Nashville, TN: Counselor Recordings and Tests.

Korabik, K., \& PITT, E. J. (1980). Self concept, objective appearance, and profile self perception. Journal of Applied Social Psychology, 10, 482-489.

Lerner, R. M., Orlos, J. B., \& Knapp, J. R. (1976). Physical attractiveness, physical effectiveness, and self concept in late adolescents. Adolescence, 11, 313-326.

Lewit, D. W., \& Virolainen, K. (1968). Conformity and independence in adolescents' motivation for orthodontic treatment. Child Development, 39, 1189-1200.

Rosen, G. M., \& Ross, A. O. (1968). Relation of body image to self concept. Journal of Consulting and Clinical Psychology, 32, 100.

Zion, L. C. (1965). Body concept as it relates to self concept. Research Quarterly, 36, 490-495.

(Manuscript received for publication January 20, 1984.) 